\title{
SIGNIFICANCE OF VARNA AIRPORT FOR BULGARIAN TOURISM
}

\author{
DOI: https://doi.org/10.18509/GBP210245v
}

UDC: 338.48:656.7(497.2)

656.7.072:311.2(497.2)”2010/2019"

\author{
Vanya Vasileva ${ }^{1}$ \\ Violeta Ilieva ${ }^{2}$ \\ ${ }^{1}$ Konstantin Preslavsky University of Shumen, Bulgaria \\ ${ }^{2}$ Varna Aiport, Bulgaria
}

\begin{abstract}
Nowadays, air transport is closely related to tourism industry and contributes to faster and more convenient long-distance travel. As a result, air transport has recently overtaken road transport and has become a priority mode of transportation for tourist purposes.

Air transport in Bulgaria and the private airport of Varna have a centuries-old tradition. In connection with the growth of tourism industry in Bulgaria, the importance of air transport and, respectively, of Varna Airport for the transport of passengers - tourists to and from the country - is growing.

This paper studies the specifics of Varna airport in terms of its tourist functions. The working hypothesis is that Varna Airport is a key factor for the development of tourism not only in the city but also in the region, offering fast and convenient connections with many cities in Europe and the Middle East. Its ability to welcome and send tourists has considerable potential. It presents and analyzes data about the significance of the airport for tourism in the region and the country as a whole.
\end{abstract}

Keywords: Varna airport, passenger transport, tourism, tourist flows

\section{INTRODUCTION}

Nowadays, air transport is closely linked to the tourism industry and contributes to faster and more convenient long-distance travel. As a result, air transport has already overtaken road transport and has become a priority mode of transport for tourist services. Air transport contributes to economic growth, tourism development, employment. Bulgaria is well known in the tourist markets as a destination offering many and varied tourist opportunities. The combination of sea, mountains, various sights and events, as well as various types of tourism makes it desirable for many foreign tourists.

The city of Varna is known as the sea capital of Bulgaria, offering different types of tourism - sea, cultural, congress, SPA, wellness, sports, shopping, events and more. In this regard, it can be said that Varna is gradually becoming a year-round tourist destination. Varna is also the most important transport connection of Bulgaria with Russia and one of the most important transport and tourist centers for the Black Sea region.

The possibilities of Varna Airport for processing passengers and cargo have a great effect on the development of the transport network, tourism and trade in northeastern Bulgaria. The working hypothesis of the current study is that Varna Airport is a key factor for the development of tourism not only in the city but also in the region, offering fast and convenient connections with many cities in Europe and the Middle East. Its ability to welcome and send tourists has considerablepotential. The purpose of this study is to analyze the activities of Varna Airport and its impact on tourism development. 


\section{METHODOLOGY}

To achieve the set goal and objectives, various research methods have been used:

- collection, processing and analysis of significant volumes of statistical information, as well as own calculations based on it;

- chronological method, tracking the development over time of the studied object and the issues related to its activity;

- collection and review of available literature sources;

- general logical methods - analysis, synthesis, comparison, generalization, etc.

The scope of the present study is particularly relevant in relation to the growing role of air transport in tourism. It can be argued that the problem is understudied in terms of specific sites, such as Varna Airport. It is partially represented in the works of $\mathrm{H}$. Nikolova and H. Georgiev as it is considered mainly in historical terms. [2] [4]

The present study analyzes the activity of Varna Airport for the period 2010-2019. The latest up-to-date data for 2020 are not yet fully available, but it is not difficult to assume that in 2020 there will be serious changes related to restricting travel in a pandemic. Therefore, the specifics of the airport's operations in 2020 are only partially affected.

\section{AIR TRANSPORT AND TOURISM}

Air transport is already a leading factor in the development of tourism, as it is an integral part of the tourism industry. In 2018, 58\% of tourist trips were made by air, and this share is growing rapidly. [5] Its biggest advantage is the speed with which long distances are covered in a much shorter time than by car or railway transport. It allows you to quickly and conveniently visit many tourist destinations. As Hristo Nikolova points out, this is precisely why this type of transport is becoming increasingly important for the mobility of people and goods. In the first place are comfort and safety, which are a priority for every airline and ensure a high culture of customer service. The social benefits of aviation include expanding people's access to new cultures and destinations around the world, creating jobs and improving the living standards of the local population through tourism, providing connections to hard-to-reach areas and areas covered by social exclusion, contributes to the economic development of the regions and contributes to the sustainable development of tourism [3]. The supply of transport services by low-cost airlines in recent years has increased the demand for air transport, leading to a significant reduction in flight and customer service costs without compromising flight safety.

Modern trends are aimed at increasing convenience, comfort and even providing luxury. However, for low-cost airlines, the travel conditions are subject to minimum comfort requirements. The requirements for safety and security of flights are increasing, as well as for the reduction of noise pollution, as well as the emission of harmful gases.

According to Nikolova [4], the development of air transport is extremely important for the national economy - jobs are created, trade and connections of local companies and citizens with contractors and partners from around the world are facilitated. Its technical and economic features define it as the most economically advantageous mode of transport in the transport of passengers and perishable goods, as well as those requiring express or urgent delivery.

The advantages and disadvantages of passenger air transport determine its role in the system of tourist services mainly for:

- implementation of long-distance mass tourist transport; 
- servicing of the organized group and individual tourism during the implementation of the main transfer or in the area of the residence;

- servicing medium- and high-paying clients in international tourism;

- carrying out tourist transport mostly during the active tourist season;

- conducting tourist trips of business (domestic or international) tourism.

The organization of tourist trips by air is carried out in two ways - through regular passenger lines or with specially rented flights (charter services). Comparisons between the pricing policy for charter and scheduled flights show that at the same cost, the airline offers lower prices for charter flights, which is due to the ability to provide a higher load on the aircraft.

In the conditions of competition, the airlines are forced to make a number of reliefs for the tourists traveling on the regular passenger routes, such as reductions in the transport prices, admission for transportation of a larger amount of luggage, etc.

Recently, inclusive and block charter flights have become widespread among airlines that are members of the International Air Transport Association. [19]

Inclusive tours are characterized by the fact that the price paid by the tourist includes, in addition to the transport price, also a night in a hotel and additional services such as a panoramic tour of the town for sightseeing, short car trips or transfer.

It is typical for charter services that not individual seats are purchased, but the entire aircraft or part of its capacity is rented. In the world practice there are a number of types of charter flights, the most common of which are:

a) One-time charter - in this case, the client orders an aircraft for certain dates (only one way or a return service), and in the interval between charter flights the airline can to use the aircraft.

b) Time charter - this type of charter is applied when the client, respectively the guarantor company finds it appropriate to rent an aircraft for a certain period, during which it is at the complete disposal of the guarantor. Time charter is advantageous for airlines because they receive guaranteed pay. At the same time, it is very convenient for the guarantor, especially if they needs to perform mass transport for a certain period.

c) Charter chain - characteristic of this type of charter is that the leased aircraft arrives at the starting point for charter services and from this point operates charter flights to one or more points under the scheme "round trip". The flights of the aircraft to the starting point for charter services are not paid by the guarantor - these flights are usually unproductive for the airline.

d) Block charter - the trips are made on regular airlines, but are booked in advance, i.e. hey block a number of passenger seats on aircraft. The guarantor pays for the whole block of passenger seats regardless of its actual use. Block charter services are profitable for the airlines only during periods of reduced demand for air services, because the block seats are sold at prices that are significantly lower than the respective tariffs.

Charter services are performed on the basis of a previously concluded charter contract (aircraft rental). In principle, the formalities relating to the flights are borne by the carrier. These include settling immigration, customs, border and other issues, as well as obtaining permission from the aviation authorities to operate a charter flight. The main obligation of the guarantor is to ensure the timely movement of passengers and their luggage to the airport. The basis for charter flights is the request from the guarantor, submitted to the airline up to 15 days before the flight. The request shall indicate the name of the guarantor, the date of the flight and other information required by the airline. 
A variety of traditional charter tourist trips are one-day plane trips to practice winter sports, hunting, fishing and more. In order to ensure a more rational use of air transport in tourist travel, it is appropriate to apply such forms of organization of transport activities as winter charters, off-season charters, charters for weekly trips throughout the year and others. In some countries acquire popularity the so-called weekend trips with individual or group rates, as well as specialized short trips. In this regard, there are great opportunities for the development of active international tourism.

A well-organized acquisition activity can help to attract more tourist traffic. Acquisition is a method of work applied by specially charged employees of the airlines in order to attract more customers to use the relevant transport services. It consists in establishing close and continuous contact with the possible sources of passengers for air transport tour operators, travel agents and others. [1]

The technical improvement of the material and technical base of the passenger air transport, the organizational and product innovations in its activity in combination with the favorable prices of the transportations will confirm the aircraft in the future as a preferred means of transport for mass tourism. [14]

As for the Northeast Planning Region in Bulgaria, K. Nedeva and E. Ganchev found that the impact of income on passenger traffic is very strong, but has little statistical significance. The effect of the impact of passenger traffic on the income of the population is weak, but statistically significant, with a lasting manifestation. Therefore, air transport has a significant effect on the sustainable development of the region in its socio-economic dimensions. [3]

\section{ORIGIN AND DEVELOPMENT OF AIR TRANSPORT IN BULGARIA AND VARNA}

In the autumn of 1894, with the support of the Varna Regional Commission, 19-year-old Haralampi Jamdzhiev made the first flight of an aerodynamic device in Bulgaria. In 1911 the program for building the Bulgarian aviation started. On April 1, 1922, an aviation department was established at the Ministry of Railways, Posts and Telegraphs, located at Bozhurishte Airport. The aim is to arrange a passenger air network between the largest cities. This is the first attempt to create civil aviation in Bulgaria, which has been developing and transforming over the years. In 1947 a permanent air line was opened between Varna and Sofia. After the airline company the Balkans was closed in November 2002, a month later the government of Simeon Saxe-Coburg-Gotha created a new state airline, called Bulgaria Air [18] Today the main body for air transport management in Bulgaria is the Ministry of Transport, Information Technology and Communications [6] and in particular the General Directorate of Civil Aviation Administrations [15].

Varna's first Tihina Airport was located near Asparuhovo. It occupied an area of 10001500 decares. On May 9, 1948, the new airport of Varna was opened and the first plane with official guests from Sofia landed.

The first artificial pavement on the runway was laid in 1961. In 2011/2012 rehabilitation of the runway for taking off and landing has been done. A layer of asphalt concrete with polymer-modified bitumen has been laid. The side safety strips have been widened to 7.5 $\mathrm{m}$. Thus, the total width of the runway is $60 \mathrm{~m}$.

During the rehabilitation, a new drainage and lighting system was built and an adaptation was made in the connection areas of the runway for taking off and landing with the taxiways. The track was put into operation again on February 29, 2012. 
The current Terminal 1 was built in 1972. It has been expanded several times over the years. It is a building on three levels. Since 2013, this facility has not been used for passengers because Terminal 2 has sufficient capacity to cover current needs.

In December 2011 - August 2013 the construction works on the new terminal 2 are carried out. It was opened on August 18, 2013. It has a capacity of 1,800,000 passengers per year and has 25 check-in counters. Its total area is $18,000 \mathrm{~m} 2$. The terminal buildings are designed so that their capacity can be increased in addition to the existing part. [4]

\section{INFRASTRUCTURE AND SUPERSTRUCTURE}

Terminal 2 is designed according to the requirements of Fraport Twin Star Airport Management $\mathrm{AD}$ for a modern, functional and sustainable airport complex. The concept is for a flexible structure that will allow future expansion as the number of passengers increases.

Today the airport is located on the territory of 2 municipalities - Varna and Aksakovo, 8 $\mathrm{km}$ northwest of Varna. Its area is 2,414 decares and has 5 taxiways. The largest type of aircraft that serves the airport is the Boeing 747. Landing on runway 09 (from the west) can be done in conditions of reduced visibility. [8]

The following facilities are located within a radius of $15-20 \mathrm{~km}$ :

- Port of Varna

- Developed railway junction

- European roads E70, E87, national road A-2 (Hemus highway) to Sofia and A-5 (Black Sea highway) to Burgas.

- Developed commercial and industrial areas, incl. 4 shopping centers and numerous representative offices of companies

Within a radius of $40 \mathrm{~km}$ from the airport are the resorts Golden Sands, Riviera Holiday Club, Sunny Day, St. St. Constantine and Elena and Albena, which attract millions of visitors every year.

The runway 09/27 has the following dimensions: length $-2,517 \mathrm{~m}$, width $-45 \mathrm{~m}$, side safety strips $2 \times 7.5 \mathrm{~m}$. The platform of Varna Airport is located north of the runway. The pavement is concrete laid on fields. The platform consists of a total of 24 stands. 14 stands are for positioning / exiting the aircraft on their own, and 10 stands are for taxiing when positioning / towing when exiting. The total capacity of the platform meets the needs of the traffic. The aircraft traffic area is to the south. [8]

Terminal 2 is a one-level building with an approximate built-up area of 17,600 m2. With full operational functionality, the terminal meets the needs of peak traffic in the summer. Based on the traffic forecasts and the program of the facility in the first stage, the terminal will be able to serve the expected needs for departing passengers by 2026 and for arriving passengers by 2031. The planned extensions of Terminal 2 will be realized during the second and third stages of development. It is envisaged that these extensions will be made on both sides of the building, preserving the architectural and functional concept of the facility. [8]

The number of passengers at Varna Airport varies considerably in summer and winter. Therefore, the operational area of Terminal 2 can be separated by means of movable barriers and reduced during the off-season in order to minimize costs. The aim is, on the one hand, to ensure reduced activity in the winter and, on the other hand, to offer diversity in the passenger stay and a good range of shops and restaurants. Adaptation of Terminal 2 to passenger traffic is achieved by creating a central area that operates throughout the year. There are key locations for processing, retail, and ancillary areas. The terminal areas 
of the terminal can be closed during the winter when the passenger traffic is reduced. In Terminal 2 there are no physical barriers for persons with reduced mobility. The terminal has offices for information and assistance to people with physical disabilities or reduced mobility.

In order to create and maintain a positive impression on arrival and departure from Bulgaria, the exterior design includes accents aimed at preserving the holiday spirit of passengers.

The latest EU security regulations set higher space requirements than in the past. In this regard, the public and guarded areas of Varna Airport are separated by a fence. The transition from the public to the protected area is possible only after inspection.

The building of the new passenger terminal has a centralized checkpoint for checking passengers and staff. The centralized checkpoint for passengers is located in the departure area. All departing passengers - for domestic and international flights, must pass through this checkpoint. In the first stage of its construction, it is equipped with $9 \mathrm{X}$-ray machines, 5 pass-through metal detectors (WTMD), hand-held metal detectors (HHMD) and a CCTV surveillance system. The check of passengers' hand luggage is performed by 2 automatic X-ray machines located behind the check-in area. The new system also has an explosive (ETD) detector.

All cars enter and exit the guarded zone through a checkpoint. It is equipped with an Xray machine, a pass-through metal detector (WTMD), hand-held metal detectors (HHMD), an explosives detector and a CCTV surveillance system. The existing perimeter fence and road network fully comply with the regulations.

At Varna Airport, the design phase of the rehabilitation and extension of the 1220-meterlong Eco taxiway has been launched. The investment project has an expected value of about 4 million BGN. There are ongoing improvements of the construction and firefighting measures in the building of the hangar. [17]

\section{ORGANIZATION AND MANAGEMENT OF THE AIRPORT ACTIVITIES}

Since 2014, two ground operators have been operating at Varna Airport - Fraport Twin Star Airport Management AD and Golder Handling Bulgaria, respectively. In addition to them, 17 other companies operate at the airport, some of which provide self-service for the aircraft they operate. Varna Airport is a public state property, transferred on concession for a period of 35 years as of 2006 to Fraport Twin Star Airport Management $\mathrm{AD}[4]$

Fraport Twin Star Airport Management AD is a German-Bulgarian company concessionaire of Burgas Airport and Varna Airport, with $60 \%$ participation of the world airport operator Fraport AG and with $40 \%$ owned by Airport Services - Bulgaria. So far, more than 395 million private capitals have been invested in the expansion and modernization of the two airports. [10] The investments are aimed at improving the infrastructure and all technical facilities and equipment, as well as training and retraining of staff. Fraport Twin Star Airport Management AD in Varna and Burgas employs more than 700 permanents and about 1200 seasonal employees. [11] There is a Center for Career Development of Employees as continuous training and professional qualification are part of the company's corporate policy. [9] [16] [17]

The management of aircraft taxiing is carried out in close cooperation with the State Enterprise Air Traffic Management. Varna Airport is governed by a Board of Directors, which includes a Chief Executive Officer, a Chief Financial Officer and a Chief Coordination Director. [13] [17] 
From March 2020, in order to prevent the infection with Covid-19 at Varna Airport, all recommendations and instructions received from the relevant Bulgarian and world health authorities are strictly followed. The joint efforts with the competent employees of the Regional Health Inspectorate - Varna and the police department of Varna Airport include registration of all arriving passengers in the border control system and additional collection of information through questionnaires filled out by passengers arriving from risky destinations.

In the arrival hall of Terminal 2, before the counters for border checks, there is an installed thermal camera, which is serviced by specialized teams of the Regional Health Inspectorate - Varna in accordance with the flight schedule and the corresponding risk associated with the country of origin. In addition, there is constant communication with the airlines that serve Varna Airport, for better control and awareness on both sides. Safeguards are provided for airport services and other necessary supplies for crisis management by Covid-19. A number of measures have been taken to tackle the spread of the infection, including an enhanced cleaning and disinfection regime, regular ventilation and cleaning of premises and vehicles, separation of passengers arriving from high-risk destinations and the prevention of non-travelers at airport terminals. [12]

\section{OPERATING AIRLINES, FREQUENCY AND DIRECTIONS OF FLIGHTS}

In the winter of 2020 - 2021 Varna Airport offers direct flights to 17 destinations in 10 countries (Table 1). These destinations are served year-round.

Table 1: Year-round destinations of flights from Varna Airport. [data source 8]

\begin{tabular}{|c|c|c|}
\hline COUNTRIES & DESTINATIONS & SERVICE AIRLINE \\
\hline \multirow[t]{7}{*}{ Germany } & Frankfurt (Haan) & \multirow{15}{*}{ WizzAir Hungary } \\
\hline & Nuremberg & \\
\hline & Berlin & \\
\hline & Munich (Memmingen) & \\
\hline & Dortmund & \\
\hline & Hamburg & \\
\hline & Cologne & \\
\hline \multirow[t]{2}{*}{ Great Britain } & London (Luton) & \\
\hline & Liverpool & \\
\hline Belgium & Brussels (Sharleroi) & \\
\hline The Netherlands & Eindhoven & \\
\hline Austria & Vienna & \\
\hline Czech Republic & Prague & \\
\hline Cyprus & Larnaca & \\
\hline Israel & Tel Aviv (Ben Gurion) & \\
\hline Bulgaria & Sofia & Bulgaria Air \\
\hline Turkey & Istanbul & Turkish Airlines \\
\hline
\end{tabular}

Until 2020, year-round flights were also operated to Russia (Moscow, Domodedovo), Italy (Beragamo), France (Paris, Beauvais). The table shows that the predominant destinations are in Europe (88\%) and only two (12\%) are outside Europe, but they also belong to the European tourist region. The most prevalent are the destinations covered in Germany (41\%), which in summer serve incoming tourists, and in winter mainly Bulgarians living abroad and their families. In the period 2010 - 2019 year-round flights (domestic and international) from / to Varna Airport are operated by 5 airlines - Bulgaria 
Air, Wizz Air Hungary, Austrian Airlines, S7 Airlines, Turkish Airlines, but in 2020 four of them remain. Of the low-cost carriers, year-round scheduled flights are operated by Wizz Air Hungary, which operates the largest number of flights and covers the most destinations. Until 2018, their number was 8, and from 2019, after a second aircraft of the airline was based at Varna Airport, the flights increased by 6 . The destinations are mainly to European airports. A worrying fact is observed with the operating airlines - a strong monopoly of only one airline, which hides risks for the quality of the provided services and / or for increased prices in the future. The Bulgarian national carrier (Bulgaria Air) is very poorly represented, serving just one line, the only domestic line.

During the active tourist season, the flights increase. In 2020, they are up to 28 destinations in 15 countries (Table 2).

Table 2: Directions of seasonal flights served by Varna Airport in 2020. [data source 8]

\begin{tabular}{|c|c|c|}
\hline \multirow{2}{*}{ COUNTRIES } & DESTINATIONS / AIRPORTS & \multirow{2}{*}{ SERVICE AIRLINE } \\
\hline Germany & Hannover & \multirow{2}{*}{ WizzAir Hungary } \\
\cline { 2 - 2 } & Baden baden & \\
\hline Austria & Saldsburg & \multirow{2}{*}{ Norwegian Air Shuttle } \\
\hline Spain & Barcelona & \multirow{2}{*}{ LOT } \\
\hline Italy & Bergamo & \\
\hline Finland & Helsinki & SiberiaAirlines \\
\hline Poland & Warsaw & NordStar Airlines \\
\hline Hungary & Krakow & Bukgaria Air Charte \\
\hline Russia & Budapest & \\
\hline Turkey & Moscow (Domodedovo) & \\
\hline
\end{tabular}

During the warm half of the year, the flights connecting Varna with a total of 9 ( 7 yearround and 2 seasonal) destinations in Germany dominate again. The flights to Austria with the additional destination Salzburg and Turkey with the additional destination Antalya, which serves mainly the tourist flow leaving Bulgaria, are increasing. Flights in 2020 to Spain, Italy, Finland, Poland, Hungary and Russia are only seasonal. They serve not only incoming tourists, but also Bulgarian tourists who have chosen these countries for their vacation. It is noticed that more airlines are included in the summer flights, but the monopoly positions of WizzAir are preserved. During the period $2010-2019$, the flights during the active tourist season were significantly more (Table 3 ).

Table 3: Directions of seasonal flights served by

Varna Airport for the period 2010 - 2019. [data source 8]

\begin{tabular}{|c|c|c|}
\hline COUNTRIES & DESTINATIONS / AIRPORTS & SERVICE AIRLINE \\
\hline Germany & Berlin (Tegel) & Air VIA \\
& $\begin{array}{c}\text { Berlin (Schönefeld), Dresden, Düsseldorf, } \\
\text { Erfurt / Weimar, Leipzig, Nuremberg, } \\
\text { Frankfurt, Hanover, Hamburg, Stuttgart }\end{array}$ & \\
\cline { 2 - 3 } & $\begin{array}{c}\text { Berlin (Tegel), Berlin (Schönefeld), Düsseldorf, } \\
\text { Cologne / Bonn, Leipzig, Münster, Munich, } \\
\text { Nuremberg, Frankfurt, Stuttgart }\end{array}$ & Bulgarian Air Charter \\
\cline { 2 - 3 } & Berlin (Tegel), Hamburg, & Bulgaria Air \\
\cline { 2 - 3 } & Düsseldorf, Frankfurt, & Germania \\
\cline { 2 - 3 } & Berlin (Tegel), Stuttgart & Germanwings \\
\hline
\end{tabular}




\begin{tabular}{|c|c|c|}
\hline & Munich & Condor \\
\hline & Munich & Lufthansa \\
\hline \multirow[t]{2}{*}{ Austria } & Vienna & Bulgaria Air \\
\hline & Vienna & Bulgarian Air Charter \\
\hline France & Paris (Orly) & Transavia France \\
\hline The Netherlands & Amsterdam & TUI Airlines Netherlands \\
\hline \multirow[t]{4}{*}{ Denmark } & Billun, Copenhagen & Primera Air \\
\hline & Aalborg, Billun, Copenhagen & SAS \\
\hline & Billun, Odense, Aalborg & BRA \\
\hline & Copenhagen & \multirow{4}{*}{$\begin{array}{l}\text { Thomas Cook Airlines } \\
\text { Scandinavia }\end{array}$} \\
\hline Sweden & Gothenburg, Stockholm - Arlanda & \\
\hline Norway & Bodo, Oslo, Trondheim, Stavanger & \\
\hline Finland & Helsinki & \\
\hline \multirow[t]{4}{*}{ Russia } & $\begin{array}{c}\text { Moscow (Domodedovo) } \\
\text { St. Petersburg } \\
\end{array}$ & Azur Air \\
\hline & Moscow (Domodedovo), St. Petersburg & NordStar \\
\hline & Moscow (Sheremetyevo) & Nordwind Airlines \\
\hline & Moscow (Domodedovo) & Yamal Airlines \\
\hline Belarus & Minsk & Belavia \\
\hline Ukraine & Kiev (Zhulyany) & Bravo Airways \\
\hline \multirow[t]{4}{*}{ Poland } & $\begin{array}{c}\text { Warsaw, Wroclaw, Gdansk, Katowice, Krakow, } \\
\text { Poznan }\end{array}$ & Enter Air \\
\hline & Warsaw (Chopin), Wroclaw, Katowice, Kosice & Bulgarian Air Charter \\
\hline & Warsaw, Katowice, Poznan & Travel Service Poland \\
\hline & Warsaw, Gdansk, Katowice, Poznan & $\begin{array}{l}\text { Small Planet Airlines } \\
\text { Poland } \\
\end{array}$ \\
\hline Lithuania & Vilnius & Small Planet Airlines \\
\hline Latvia & Riga & SmartLynx Airlines \\
\hline Estonia & Tallinn & Smartlynx Airlines Estonia \\
\hline Czech Republic & Lol, Prague & Travel Service \\
\hline Slovakia & Bratislava & Bulgaria Air \\
\hline \multirow[t]{2}{*}{ Armenia } & \multirow[t]{2}{*}{ Yerevan } & Bulgaria Air \\
\hline & & Bulgarian Air Charter \\
\hline \multirow[t]{2}{*}{ Israel } & \multirow[t]{2}{*}{ Tel Aviv } & Bulgaria Air \\
\hline & & Bulgarian Air Charter \\
\hline \multirow[t]{2}{*}{ Lebanon } & \multirow[t]{2}{*}{ Beirut } & Bulgaria Air \\
\hline & & Bulgarian Air Charter \\
\hline \multirow[t]{2}{*}{ Kuwait } & \multirow[t]{2}{*}{ Kuwait } & Bulgaria Air \\
\hline & & BH Air \\
\hline \multirow[t]{5}{*}{ Iran } & \multirow[t]{5}{*}{ Tehran } & Bulgaria Air \\
\hline & & Iran Aseman Airlines \\
\hline & & Mahan Air \\
\hline & & Meraj Airlines \\
\hline & & Qeshm Airlines \\
\hline
\end{tabular}

The table shows that the total number of airlines operating charter flights to / from Varna Airport in the period 2010-2019 is 31. They serve a total of 47 destinations from 18 countries, mainly in Europe. The most destinations (19) are served by the Bulgarian Air Charter airline. Next in activity is Air VIA, which served 12 destinations to / from different cities in Germany. Air VIA ceased operations in 2016. Of the airlines listed in the table, three more have ceased operations. These are the airline "Germania" with 
suspended operations from February 5, 2019, the airline "Small Planet Airlines" with suspended operations from November 28, 2018 and the airline "Thomas Cook Airlines Scandinavia" with suspended operations from October 30, 2019. [8] [20] The tables show that there is a negative tendency for Bulgarian air carriers to have an ever-decreasing share in the total volume of air traffic.

The great variety of operating airlines is impressive, as well as the better positions of the Bulgarian national carrier, especially in terms of the Middle East destinations. The strongest impact on the reduction of charter flights is the pandemic of 2020, but some of them were terminated earlier due to economic reasons. Therefore, the air traffic to and from Varna Airport is a dynamic quantity that changes over the years. However, the dominant number of flights connecting with a large number of airports in Germany is maintained. This is not the case with the other areas. Currently, most Middle East charters, most charter flights to Eastern European countries, as well as some charters to Western Europe have been almost completely suspended. The latter are relatively less affected by the ongoing reductions.

\section{PASSENGER FLOW ANALYSIS}

The total passenger flow (arrivals and departures) through Varna Airport has increased from 1,201,557 passengers in 2010 to 2,070,308 passengers in 2019, i.e. $72 \%$ more. The largest number of passengers passing through the airport is observed in $2018-2,265,952$ passengers. (Fig. 1). The data show a gradual increase in the total number of passengers served at the airport, with a larger increase observed after 2016. In 2019, a slight decline was reported, which significantly intensifiedin 2020.

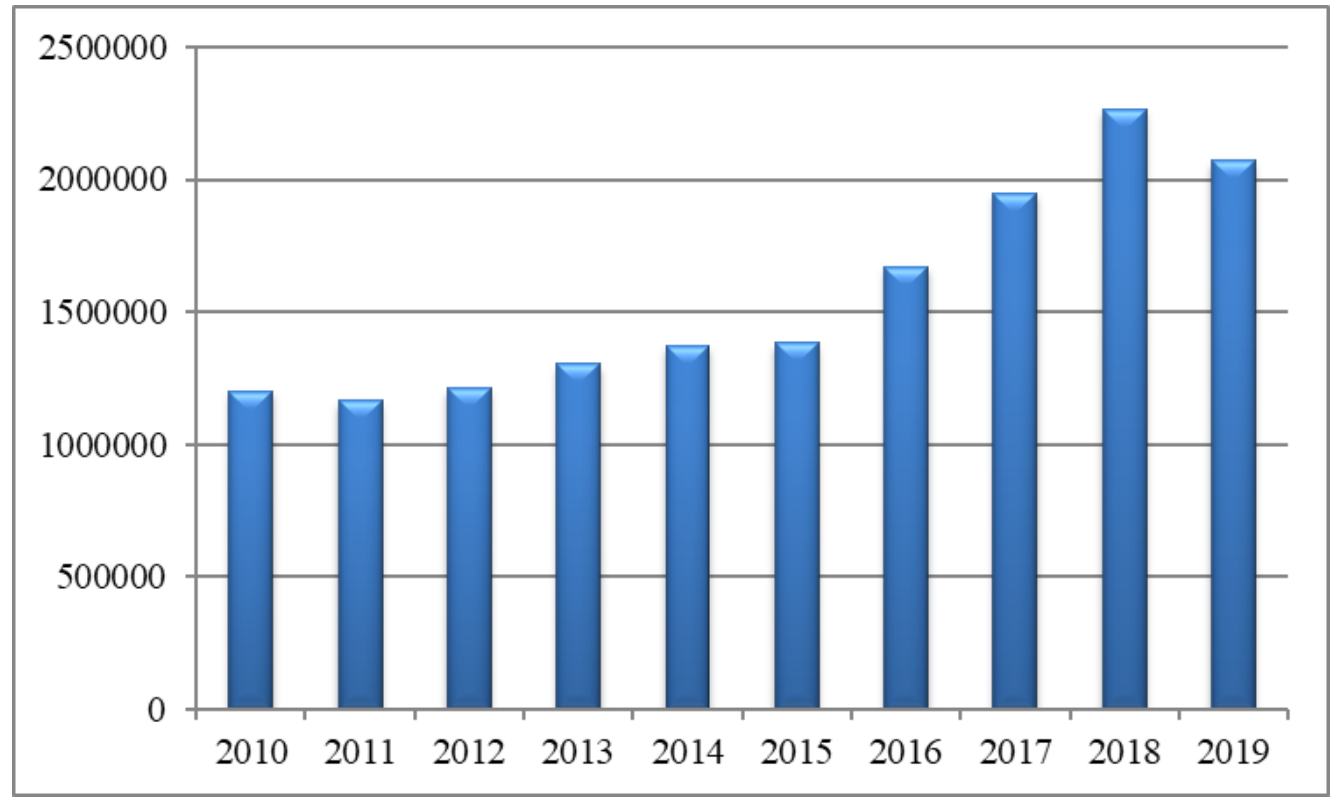

Figure. 1: Total passengers served at Varna Airport (2010-2019)

[data source 8]

The number of arriving passengers has also increased significantly, as in 2010 they were 598,785 , and in 2019 their number increased to $1,034,896$, i.e. $73 \%$ increase (Fig. 2). The growth is not uniform. It can be seen that it is more significant after 2016. In 2019, a slight decline was registered, which intensified in 2020 in relation to the pandemic. The 
changes in the number of departing passengers are similar. They are shown in fig. 3. The ratio of arriving passengers with scheduled and charter flights is shown in fig. 4.

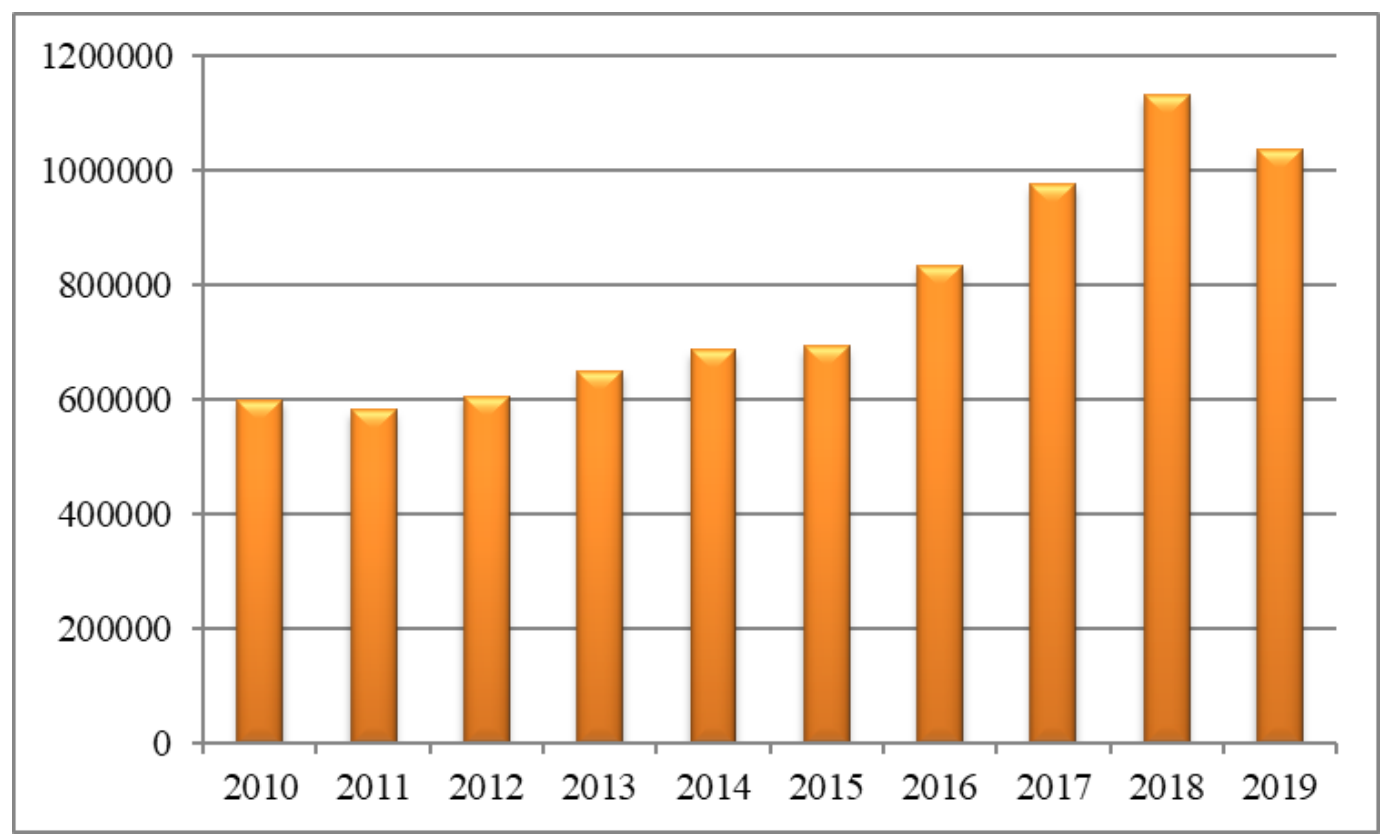

Figure. 2: Number of arriving passengers at Varna Airport (2010-2019) [data source 8]

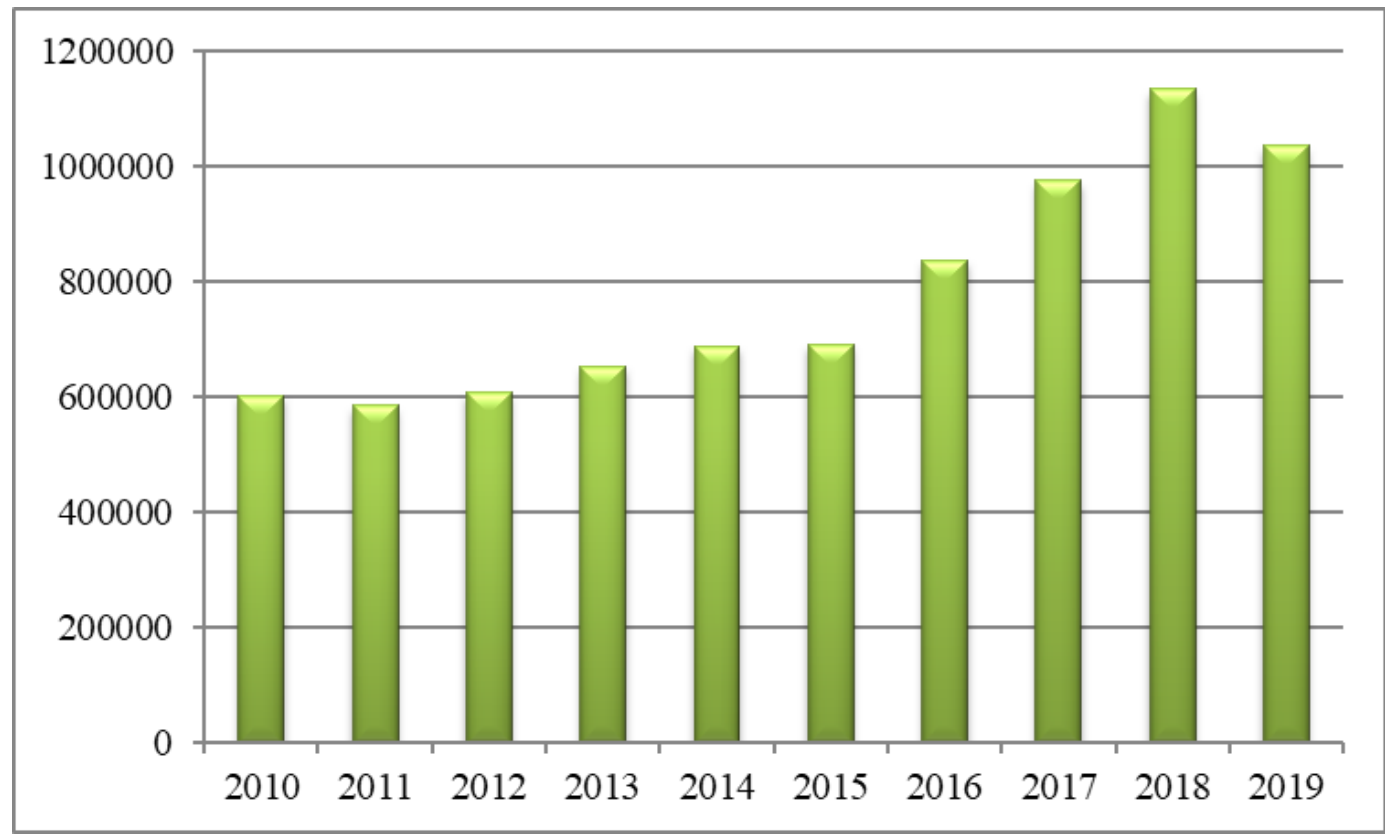

Figure. 3 Number of departing passengers from Varna Airport (2010-2019) [own calculations] 


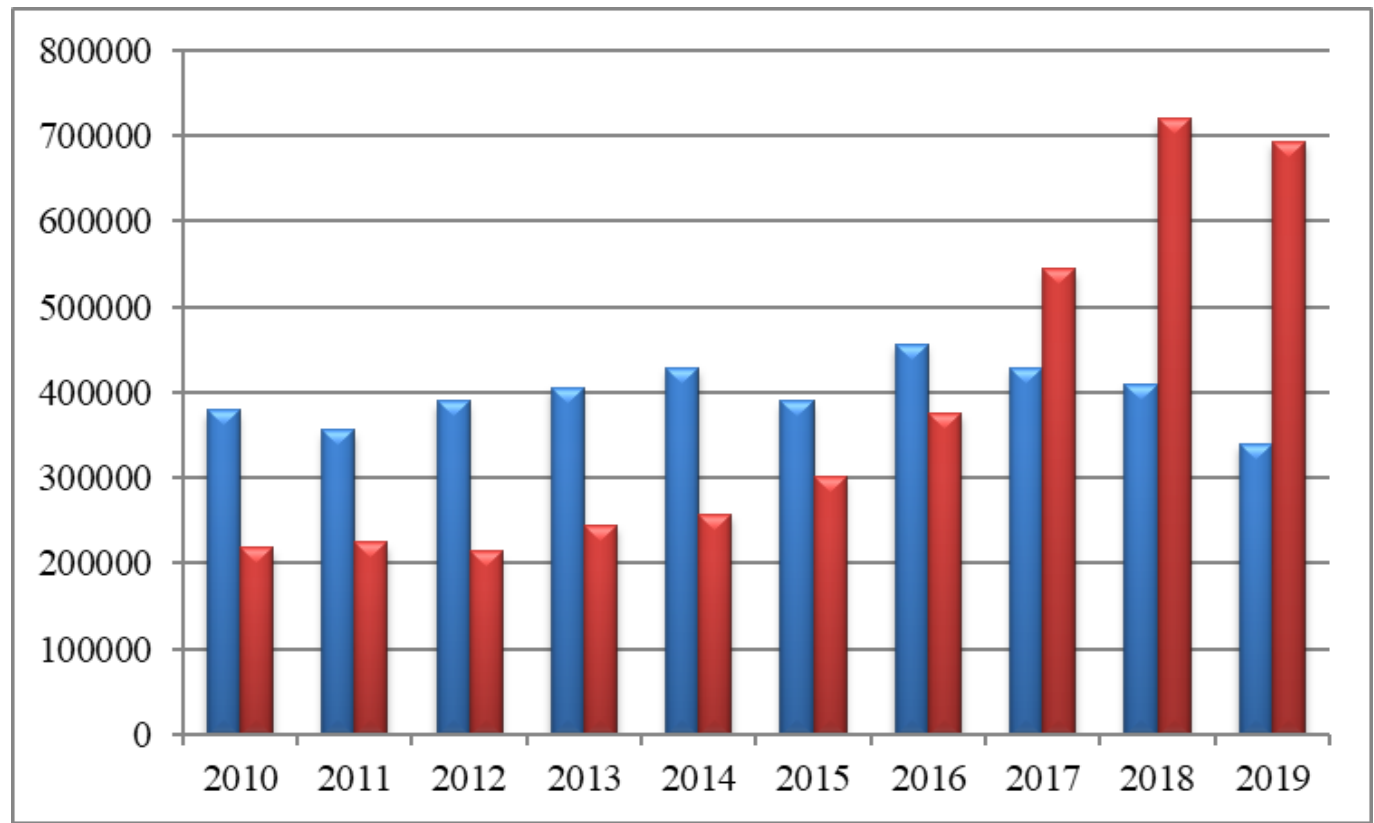

Figure.4: Ratio between arriving passengers on scheduled and charter flights (2010-2019) charter, regular lines [data source 8]

The average annual passenger flow of arriving passengers transported by international charter flights at Varna Airport for the specified period is 398,387 people, and only in 2019 the number is 339,943. In 2010, the charter passenger flow was 63\%, and had insignificant fluctuations until 2016, after which there is a tendency to decrease and reach $33 \%$ in 2019 , due to the increasing number of passengers of regular international flights. This can be considered as a positive trend for increasing the efficiency of Varna Airport. The total number of arriving passengers with charter flights at Varna Airport for the period 2010-2019 is 3,983,871.

The average annual passenger flow of arriving passengers transported by regular international routes at Varna Airport is 379,676 people. The total number of arriving passengers with regular international flights at Varna Airport for the period 2010-2019 is $3,796,768$. The total number of passengers carried with regular international flights through Varna Airport in 2010 was 218,744 people, and in 2019 - 693 611. The growth for the studied period is significant $-217 \%$.

Despite the year-round regular flights, Varna Airport retains its strong summer seasonality, which is evident from the monthly distribution of passenger traffic shown in Table 4.

Table 4: Monthly distribution of passenger flow (2010 - 2019) [data source 8]

\begin{tabular}{|l|l|l|l|l|l|l|l|l|l|l|l|l|}
\hline & I & II & III & IV & V & VI & VII & VIII & IX & X & XI & XII \\
\hline $\mathbf{2 0 1 0}$ & 8371 & 9184 & 11693 & 15195 & 46979 & 109895 & 145421 & 134665 & 72353 & 21088 & 12043 & 11898 \\
\hline $\mathbf{2 0 1 1}$ & 10101 & 8919 & 13455 & 16344 & 43790 & 116555 & 151615 & 138438 & 75039 & 7652 & $*$ & $*$ \\
\hline $\mathbf{2 0 1 2}$ & $*$ & 33 & 7683 & 13766 & 37554 & 129904 & 167674 & 146178 & 67108 & 15275 & 10481 & 9032 \\
\hline $\mathbf{2 0 1 3}$ & 8006 & 8562 & 10485 & 13177 & 41538 & 137221 & 163020 & 153763 & 74755 & 19282 & 10539 & 10239 \\
\hline $\mathbf{2 0 1 4}$ & 8279 & 9497 & 12286 & 17451 & 39870 & 147830 & 169068 & 163016 & 72787 & 22019 & 12308 & 12057 \\
\hline $\mathbf{2 0 1 5}$ & 10783 & 9844 & 12076 & 17205 & 46094 & 124410 & 174916 & 161544 & 83309 & 22955 & 13990 & 15104 \\
\hline $\mathbf{2 0 1 6}$ & 12831 & 12522 & 14688 & 19422 & 61130 & 153555 & 206358 & 189461 & 102940 & 27149 & 16091 & 18191 \\
\hline $\mathbf{2 0 1 7}$ & 13708 & 14532 & 17773 & 29674 & 67255 & 171247 & 226120 & 208112 & 119980 & 42095 & 30287 & 34175 \\
\hline $\mathbf{2 0 1 8}$ & 28204 & 25492 & 34326 & 38802 & 96437 & 199663 & 252203 & 219284 & 131977 & 45431 & 28519 & 31104 \\
\hline $\mathbf{2 0 1 9}$ & 27093 & 25378 & 29353 & 41935 & 80967 & 167205 & 210347 & 196135 & 125061 & 53741 & 36104 & 41577 \\
\hline
\end{tabular}


From the presented data it can be seen that for the period 2010-2019, the busiest months are May, June, July, August, September and October. Throughout the studied period, July has the highest traffic intensity. The lowest numbers are during the winter months and especially in January. These features correspond directly to the functions of Varna Airport related to the service of the summer tourist season. Therefore, it can be concluded that:

1. Passengers travel mainly for tourist purposes.

2. Varna Airports is a key factor for the development of tourism, providing transportation of arriving and departing tourists by air.

In the period 2010-2019 the total number of passengers arriving at Varna Airport is 7,790,300 people. Table 4 shows the percentage distribution of passenger traffic from Germany, Russia, Bulgaria, Poland and the United Kingdom, which are the top five by the number of arriving passengers.

Table 5: Arriving passengers at Varna Airport from top-five countries (2010-2019) [data source 8]

\begin{tabular}{|c|c|c|c|c|c|c|c|c|c|c|c|c|}
\hline Country & 2010 & 2011 & 2012 & 2013 & 2014 & 2015 & 2016 & 2017 & 2018 & 2019 & $Z=\varepsilon$ & $\stackrel{\circ}{.}$ \\
\hline & & & & & & & & & & & & $25,4 \%$ \\
\hline Russia & & & & & & & & & & & & $17,2 \%$ \\
\hline Bulgaria & 77495 & 59671 & 64112 & 66657 & 65052 & 65348 & 68838 & 127826 & 145224 & 131311 & 871534 & $11,1 \%$ \\
\hline Poland & 29338 & 33317 & 26685 & & 30019 & 36812 & 65713 & 79709 & 96764 & 85518 & 512571 & $6,5 \%$ \\
\hline $\begin{array}{c}\text { Great } \\
\text { Britain }\end{array}$ & 33347 & 27031 & 25136 & 30665 & 32347 & 41120 & 48197 & 66996 & 75528 & 95502 & 475869 & $6,1 \%$ \\
\hline
\end{tabular}

As can be seen, the share of passengers arriving from Germany is the largest $-25.4 \%$. In 2018 , the largest number of arriving passengers from Germany for the specified period is 297,995 . For the entire period there is a steady growth of arrivals from Germany, which, however, is variable.

For the mentioned period the total share of the arrived passengers from Russia is $17.2 \%$. The number of Russian citizens passing through Varna Airport is highly volatile due to changes in political events and visa formalities. In 2013, the largest number of passengers who arrived from Russia for the period is 191,522.

The arriving Bulgarian citizens make up $11.1 \%$ of the total number of arriving passengers. Their number almost doubled during the studied period in relation to the liberalization of air transport.

The share of passengers from Poland is $6.5 \%$. There are also very large fluctuations in the arrivals of Polish citizens. In 2018, the largest number of passengers who arrived from Poland during the period $(96,764)$ was registered in connection with good holiday offers, the increase in flights to Poland, good security measures, and the nostalgia to the 1980s, when Bulgaria was one of the main holiday destinations for Polish tourists.

Passengers arriving from the UK amount to $6.1 \%$ of the total passenger traffic. Although a decrease was reported at the beginning, an increase in arrivals was registered at the end of the period. The fluctuations can be explained by the return of the tourist market to countries such as Turkey, Egypt, Tunisia. But Bulgaria offers cheaper holidays compared to other European resorts. Low-cost flights from the UK also have an impact.

The other countries with a clear share of the total number of arriving passengers for the period 2010-2019 are Israel - 4.6\%, Austria - 4.4\%, Turkey - 3.0\%, the Czech Republic $1.8 \%$, Norway $-2.3 \%$, Belgium - $1.9 \%$, Belarus - 1.5\%, France - $1.2 \%$, Denmark - $1.4 \%$, Finland $-1.1 \%$, Lithuania $-1.1 \%$, Iran $-1.2 \%$, Estonia $-1.0 \%$, the Netherlands $-0.7 \%$, 
Luxembourg - 0.8\%, Cyprus - 0.5\%, Italy - 0.5\%, Ukraine - 0.5\%, Hungary - $0.5 \%$, Sweden - 0.5\%, Lebanon - 0.3\%, Switzerland - 0.3\%, Latvia - 0.3\%, Armenia - $0.1 \%$, Kuwait - 0.1\%, Slovakia - 0.1\%, Slovenia - 0.1\%, Serbia - 0.1\%, Greece - 0.1\%, Egypt $0.1 \%$.

Table 6 shows the top 30 destinations at Varna Airport (2010 -2019).

Table 6: Top 30 destinations (2010-2019) [data source 8]

\begin{tabular}{|l|l|l|l|l|l|}
\hline Destination & $\begin{array}{l}\text { Total } \\
\text { number of } \\
\text { passengers }\end{array}$ & Destination & $\begin{array}{l}\text { Total } \\
\text { number of } \\
\text { passengers }\end{array}$ & Destination & $\begin{array}{l}\text { Total } \\
\text { number of } \\
\text { passengers }\end{array}$ \\
\hline 1. Moscow & 1026068 & 11. Leipzig & 202675 & 21. Minsk & 122462 \\
\hline 2. Sofia & 870323 & 12. Hanover & 202840 & 22. Nuremberg & 97860 \\
\hline 3. London & 404355 & 13. Berlin & 175075 & 23. Helsinki & 86933 \\
\hline 4. Tel Aviv & 365066 & 14. Warsaw & 152297 & 24. Oslo & 87625 \\
\hline 5. Vienna & 345516 & 15. Prague & 118242 & 25. Tehran & 94431 \\
\hline 6. Dusseldorf & 311974 & 16. Stuttgart & 137580 & 26. Tallinn & 84267 \\
\hline 7. Istanbul & 203271 & 17. Cologne & 137607 & 27. Vilnius & 82297 \\
\hline 8. St. Petersburg & 241753 & 18. Hamburg & 126683 & 28. Poznan & 68995 \\
\hline 9. Frankfurt & 223292 & 19. Munich & 125867 & 29. Luxembourg & 63912 \\
\hline 10. Katowice & 195124 & 20. Brussels & 125595 & 30. Paris & 51687 \\
\hline
\end{tabular}

Table 6 shows that Varna Airport serves a variety of destinations, although flights to most of them are seasonal. Among the busiest destinations are Moscow, London and Tel Aviv in service of Russian, British and Israeli tourists, respectively. Another busy line is VarnaSofia because of the capital functions of Sofia and its distance from the sea capital. Although German passengers are predominant, German airports are lower in the rankings due to their significant number.

In 2020, there is a decrease of about $3 / 4$ in the number of flights. The largest Bulgarian charter airline - Bulgarian Air Charter - is completely grounded. It can be assumed that this directly reflects on the volume of passenger flows, which also decrease by at least 1/4.

\section{IMPORTANCE OF VARNA AIRPORT FOR THE FORMATION OF THE TOURIST PRODUCT OF BULGARIA}

Varna Airport is the third in terms of traffic in Bulgaria after the airports in Sofia and Burgas. Varna Airport is one of only two airports (along with Sofia) which reports a significant increase in the number of passengers transported during the studied period. Varna Airport serves Northeastern Bulgaria and through its convenient connections it can easily reach Sofia, Istanbul, Vienna, Moscow, and with the low-cost airline Wizz Air other major European cities such as London, Berlin, Munich, Hanover, Paris, etc. Important and promising relations with Asian countries are established in Istanbul.

Arriving passengers have convenient land transport connections, both by highways and railways. And while rail transport provides a convenient connection to the interior of the country, road transport is used to arrive at the resorts on the North Black Sea coast. Both regular bus services and car rental are used. Water transport has potential in this respect, but this potential is not yet fully exploited. Since passengers passing through Varna Airport travel mainly for tourism purposes, it can be concluded that the airport has a key role in the development of tourism, as well as on the economy and trade in the Northeast region of Bulgaria. This is the only airport in the region, as well as the only airport serving passengers in whole northern Bulgaria. With its activity of welcoming and seeing off tourists from more distant countries, the airport is assessed as a key factor for the socio- 
economic development of the Northeastern region. The airport is one of the prerequisites for this region to have the best socio-economic indicators compared to other regions in Northern Bulgaria.

Its location near the Black Sea makes it convenient for quick access to the city and the resorts that are located near it - St. St. Constantine and Elena (17 km.), Golden Sands (23 $\mathrm{km}$.), Albena $34 \mathrm{~km}$ ). Most of the tourists arriving at Varna Airport spend their holidays in these resorts. This is a prerequisite for the large number of charter flights during the summer and regular year-round flights to and from Varna Airport.

The share of Varna Airport in the total number of arrivals in Bulgaria for the period 20102019 is shown in Table.

Table 7: Significance of Varna Airport for air arrivals | [data source 7 and own calculations]

\begin{tabular}{|l|l|l|l|}
\hline Year & $\begin{array}{c}\text { Number of arriving } \\
\text { passengers at Varna } \\
\text { airport }\end{array}$ & $\begin{array}{c}\text { Number of passengers } \\
\text { arriving by plane in } \\
\text { Bulgaria }\end{array}$ & $\begin{array}{c}\text { Share of the total } \\
\text { number of arrivals in } \\
\%\end{array}$ \\
\hline 2010 & 598785 & 3183556 & 18,8 \\
\hline 2011 & 581908 & 3427055 & 16,9 \\
\hline 2012 & 604688 & 3513737 & 17,2 \\
\hline 2013 & 650587 & 3633840 & 17,9 \\
\hline 2014 & 686468 & 3839582 & 17,8 \\
\hline 2015 & 692230 & 3907021 & 17,7 \\
\hline 2016 & 834338 & 4751330 & 17,6 \\
\hline 2017 & 974958 & 5680596 & 17,2 \\
\hline 2018 & 1131442 & 6222617 & 18,1 \\
\hline 2019 & 1034896 & 6003406 & 17,2 \\
\hline
\end{tabular}

It can be seen that for the period 2010-2019 an average of $17.6 \%$ of the total number of passengers arriving by plane in Bulgaria used Varna Airport. This share is less than 1/4. Therefore, Varna Airport has a modest performance in the overall air traffic of the country and has significantly weaker positions than the leading Sofia Airport. But Varna Airport has a key regional significance.

Table 8: Contribution of Varna Airport to the tourism industry [data source 7,8 and own calculations]

\begin{tabular}{|l|l|l|l|}
\hline Year & $\begin{array}{c}\text { Number of overnight } \\
\text { stays in the Northeastern } \\
\text { region }\end{array}$ & $\begin{array}{c}\text { Number of arriving } \\
\text { passengers at Varna } \\
\text { airport }\end{array}$ & $\begin{array}{c}\text { Share of arrivals by air } \\
\text { of the total number of } \\
\text { overnight stays in \% }\end{array}$ \\
\hline 2012 & 1320107 & 604688 & 45,8 \\
\hline 2013 & 1382118 & 650587 & 47,0 \\
\hline 2014 & 1259503 & 686468 & 54,5 \\
\hline 2015 & 1328410 & 692230 & 52,1 \\
\hline 2016 & 1577437 & 834338 & 52,9 \\
\hline 2017 & 1662437 & 974958 & 58,6 \\
\hline 2018 & 1778345 & 1131442 & 63,6 \\
\hline 2019 & 1784731 & 1034896 & 58,0 \\
\hline
\end{tabular}

The above statement can be proved by Table 8 . It compares the number of overnight stays in the Northeastern region and the total number of passengers arriving at Varna Airport. Such a comparison is appropriate because air travelers arrive from relatively distant places, which implies the realization of overnight stays. In 2019, the share of passengers arriving via Varna Airport is $58 \%$ of the number of overnight stays in the Northeastern region. This share varies from $46 \%$ (2012) to 64\% (2018). Therefore, it can be 
summarized that more than half (on average 54\%) of the tourists in the region arrive through Varna Airport. Therefore, a smaller part of the tourists arrive by the other types of transport, and the air transport represented by a single site (Varna Airport) is leading in the transfer of the tourist flows in the region, and this is especially true for international tourists. These data and the analysis confirm the working hypothesis, namely that Varna Airport is a key factor for the development of tourism not only in Varna but also in the region, offering fast and convenient connections with many cities in Europe and the Middle East. Varna Airport is comparable in terms of functions and load with other airports in the Balkans, such as the airports in Split, Rijeka (Croatia), Ohrid (Northern Macedonia), Kavala, Rhodes, Corfu (Greece) and others. Although with similar functions related to the service of tourists, Varna Airport lags behind the airports in Bourgas (Bulgaria), Dubrovnik (Croatia), Thessaloniki (Greece) and others.

\section{CONCLUSION}

Varna Airport has a leading role in the development of Northeastern Bulgaria and in particular the Northern Black Sea coast in social and economic terms. It can quickly reach many cities in Europe and the Middle East. This is a prerequisite for the interest of foreign tourists and business representatives to our country and in particular the city of Varna and the region. The strategic location, which is due to the nearby transport links - Varna port, bus station and Varna railway station, determine the airport as a key transport factor in the region. It can be said that Varna Airport serves almost all tourist traffic as far as international tourists to the North Black Sea coast are concerned.In the last ten years, Varna Airport has seen an increase in flights and passengers. This is due, on the one hand, to the growing number of foreign tourists wishing to rest on the Bulgarian Black Sea coast and see the cultural sights of Varna and the region, and on the other hand, to the boost of year-round flights operated by the low cost airline Wizz Air to major European cities.

The opening of new routes will further stimulate trade and tourism in the city and the region, which is a prerequisite for creating more new jobs, which leads to higher living standards. However, the uneven distribution of flights makes it difficult to use them effectively. Investment in expanding the airport's terminals in response to the growing passenger flow could be considered as a recommendation. During certain days of the summer months and at peak hours, about 1,500 passengers per hour passed through the airport which led to a large congestion in front of the counters for handling passengers and luggage, in front of the security centers and the counters for border control. ${ }^{8}$ The expansion of these areas will lead to greater efficiency and will ensure greater convenience in passenger service.

New attractive commercial areas can be created, such as restaurants, coffee bars, children's corners and so passengers will be able to have a better time before the flight.

At the moment, the airport is facing challenges that need to be addressed, such as the growing traffic, on the one hand, and on the other, its uneven distribution of flights on certain days of the summer months. That is why it is important to solve the problems related to the infrastructure and staff to increase the level of service. All this will be a prerequisite for a quality service for the passing passengers and will strengthen the position of the airport as a key factor for the development of tourism in the region. 


\section{REFERENCES}

[1] Bakalova, V., Organization of the transport activity in tourism, University Publishing House "Economy", UNWE, Sofia, 2008, (p.51-55)

[2] Georgiev, H., Yolov, G., To the sky, Publishing house "Narodno delo" Ltd., Varna, 1997.

[3] Nedeva, K., E. Ganchev, Air transport - a factor for sustainable development of the region, University of Economics - Varna, pp. 225-237, 2017.

[4] Nikolova, H., Air Transport in Bulgaria, Publishing House - UNWE, Sofia, 2017.

[5] UNWTO, International Tourism Highlights, 2019 edion

[6] Ministry of Transport, Information Technology and Communications, https://www.mtitc.government.bg/bg/category/262/vuzdushen-transport

[7] National Statistical Institute, https://www.nsi.bg

[8] Varna Airport

[9] https://aeropress-bg.com/news/bulgaria/

[10] http://stroitelstvoimoti.com

[11] https://transportal.bg

[12] https://varna-airport.bg

[13] https://www.bulatsa.com

[14] https://www.bg-ikonomika.com

[15] https://www.caa.bg/

[16] https://www.chimimport.bg

[17] https://www.fraport-bulgaria.com

[18] http://www.gradvarna.com/airport.htm

[19] https://www.iata.org/

[20] https://www.planespotters.net/airline/Thomas-Cook-Airlines-Scandinavia 